MA in Psychology, leading sociologist at the Department of Methodology and Methods of Sociology, Institute of Sociology of the National Academy of Sciences of Ukraine, Kyiv

\title{
Demoralised but not depraved: Why societal lack of norms disheartens people but does not necessarily make them commit moral transgressions ${ }^{1}$
}

The phenomenon of anomie, despite having been studied for over a century and therefore considered to be one of the most exhaustively studied topics in sociology, still engages the minds of social scientists, along with researchers from other fields. What makes them address this phenomenon over and over again and look at it each time from a different angle is apparently the overwhelming (and often irreversible) impact of anomie on both the individual and the society as a whole. At this juncture, the widely discussed thesis about a strong link between anomie and moral decline is probably worth specifying or revisiting. This thesis, however convincing it may sound, begs a number of questions. The first one is related to what, actually, should be understood by anomie in this respect. Is this what E. Durkheim referred to as dereglement (which literally means "disturbance") and associated with insatiability of human passions and desires in a situation where there is no exterior social force to curb them - or is this what R. K. Merton explained as a result of a disjunction between "culturally prescribed aspirations" of a society and "socially structured avenues for realising those aspirations"? Or, perhaps, we adhere to R. M. MacIver's approach, who asserted that anomie is "the breakdown of the individual's sense of attachment to society... the

1 This paper was presented at a round-table discussion published in "Sociology: Theory, Methods, Marketing”, 2019, 1 (pp. 129-144).

(C) O.Maksymenko, 2019 
state of mind of one...who no longer has any sense of continuity, of folk, of obligation... responsive only to himself, responsible to no one". Which aspect - individual or institutional - do we bring to the forefront while attending to the anomie phenomenon? ${ }^{1}$

The next question concerns the term "anomie" itself and what it covers. In Greek, where this word came from, "anomie" ( $\alpha$ vouía) means "lawlessness". It is also rendered as "normlessness". However, a situation where there are neither laws nor norms is barely conceivable. As Merton aptly noted, "no society lacks norms governing conduct". Even the most primitive societies were governed by laws, albeit unwritten; even the most unjust and inhumane ones had an elaborate set of rules (and sophisticated ideologies too) which allowed committing all those injustices and atrocities. So, an "anomic society" is not the one where all the laws and norms have ceased to exist. Rather, it is marked by emergence of something new that we are not accustomed to and for this reason feel confused, something that runs counter to our well-established system of values and rules (or to what we see as "lofty ideals"), something that disrupts our everyday life and makes us miss "the good old days". Needless to say, we spend enormous energy trying to adjust to such a precipitous change. A picture like this is common to transitional societies (which is confirmed by numerous research studies on post-communist and post-totalitarian anomie), but it is not confined to them. Anomie is deeply entrenched in countries with a long history of war (Iraq, Afghanistan, etc.), in societies which practiced racial segregation (South Africa) and, quite expectedly, in economically disadvantaged countries. On the other hand, anomie may also plague prosperous and technologically advanced countries such as the USA and Japan. S. F. Messner and R. Rosenfeld in the work "Crime and the American dream" (1997) underlined that American society is in a permanent state of anomie and linked this state to "competitive individualism" espoused by many Americans and their obsession with economic success. J. P. Azzopardi wrote about "America's overdose of anomie", while R. Kim Fong Yong and Y. Kaneko addressed the "hikikomori" problem (deliberate social withdrawal among Japanese youngsters) and defined it as "anomic response" to "difficulties". Thus, it is not necessarily political or economic turmoil that leads to anomie. Anything that is alien to us but has to be accepted, anything that is imposed on us by society but hard (or nearly impossible) to achieve may trigger anomie-like reactions. Viewed from this perspective, anomie is akin to cognitive dissonance and social maladaptation; thus, it should be interpreted as a "state of mind".

Therefore, last but not least is the question of anomie indicators with regard to an individual and his/her proneness to immoral behaviour. Why do we conclude that someone is experiencing anomie, whereas someone else is not? What makes us assume that someone marked as "anomie-ridden" will necessarily commit a transgression? Since 1956 (the year when L. Srole suggested the first ano-

1 For more detail see: Durkheim, E. (2013). Le Suicide: Etude de sociologie. Paris: Presses Universitaires de France; Merton, R. K. (1938). Social structure and anomie. American Sociological Review, 3(5), 672-682; MacIver, R. M. (1950). The ramparts we guard. New York: Macmillan Publishers. 
mie scale), quite a few scales (Dean, Fischer, McClosky \& Schaar, Mezruchi, Teevan, Winslow, etc.) have been devised to "capture" and quantify this elusive but pervasive phenomenon, and a host of empirical studies have been conducted. A vast array of characteristics has been attributed to anomie: from lack of trust in authorities and social isolation (Srole) to a feeling of despair and confusion (Mestrovic). Fetishism of money (Messner \& Rosenfeld), political inefficacy (Carkoglu \& Cagin Bilgili), a sense that life is meaningless (Martin), a feeling of awkwardness (McClosky \& Schaar), tendency to reject social norms (Baumer, Bjarnason), self-interested behaviour (Konty) and the like are also on the list. Indeed, it seems impressive - but which of these characteristics are really coupled with immorality? Well, fetishism of money is believed to propel people into crime, especially if there are few - if any - legitimate means of getting what they want. Tendency to reject social norms will, more often than not, result in anti-social behaviour too. However, let us not forget that social norms are not immutable, and defying some of these norms may be more moral than conforming to them.

Ye. Golovakha and N. Panina used the term "anomic demoralisation"1 (1996) to describe the state of a society where both the economy and political institutions had collapsed, and ordinary people were struggling to survive. But "demoralisation" involves a loss of confidence or hope. "Demoralised" does not mean "morally bad", although does not rule out the possibility of becoming like that.

The thesis about a link between anomie and moral decline works well at societal level, which is illustrated by high suicide and homicide rates, numerous property crimes, as well as by justification of tax evasion, petty corruption, domestic violence, etc. among the general public. However, in order to determine the degree to which this thesis can be applicable to the individual, further extensive research is needed. In any case, living even in a "totally anomic" society does not mean "blending into the crowd" and starting to act immorally. History provides abundant examples of people who lived in unimaginably unfair and dishonest societies but, nonetheless, epitomised the best human qualities.

Received 12.02.2019

\section{OL'HA MAKSYMENKO}

\section{Demoralised but not depraved: Why societal lack of norms disheartens people but does not necessarily make them commit moral transgressions}

Since the early days of sociology, the anomie phenomenon has interested many social scientists. A number of theories have been developed, a host of empirical studies (including cross-national) have been performed since Emile Durkheim described this phenomenon and introduced the

1 Golovakha, E., \& Panina N. (1996). Democratisation in the Ukraine under conditions of post-totalitarian anomie: The need for a new human rights developmental strategy. In H. Dekker, R. F. Farnen, D. B. German, \& R. Meyenberg (Eds.), Democracy, socialisation and conflicting loyalties in East and West: Cross-national and comparative perspectives (pp. 242-261). London, England: Palgrave Macmillan. 
"anomie" term. Still, there is no general consensus among scholars on what anomie is and what it is not. A hard-and-fast definition of anomie has not yet been given, and what is more, researchers look at this phenomenon from at least two different perspectives: individual and institutional, explaining it as a "state of mind" or a "state of society" respectively. In terms of society, anomie has mostly been associated with malfunctioning social institutions and breakdown of moral standards, as is evidenced by high crime rates and public justification of unethical behaviour. On the other hand, living even in a "totally anomic" society and experiencing a whole range of anomie-driven emotions and reactions does not necessarily mean acting immorally. To what extent is the thesis about a link between anomie and moral decline of society applicable at individual level? The author seeks to answer this question.

Keywords: anomie as a "state of mind", anomie as a "state of society", anomic demoralisation, moral decay, moral principles, standing out from the crowd 